\title{
A RESEARCH STUDY ON THE ESSENTIALITY OF MEDICAL AWARENESS CAMPAIGNS / PROGRAMS FOR COLLEGE STUDENTS AT THE PUBLIC SECTOR IN KARACHI, PAKISTAN
}

\author{
Anila Fatima Shakil \\ Assistant Professor, \\ Department of Education, Jinnah University for Women, \\ Sindh, Pakistan \\ Email: afs28@yahoo.com

\section{Rabia Abdul Karim} \\ Assistant Professor, \\ Department of Education, Jinnah University for Women, \\ Sindh, Pakistan \\ Email: drrabiaakarim@gmail.com

\section{Urooj Fatima} \\ Researcher, \\ Department of Education, Jinnah University for Women, \\ Sindh, Pakistan \\ Email: alina_95@hotmail.com
}

\begin{abstract}
This research study is conducted on the essentiality of medical awareness campaigns/programs in public colleges, as it is seen that there is a dire need of providing students with many medical and health related information. This research is purposed to enlighten this issue and to make colleges to pay attention and take the initiatives of conducting medical awareness campaigns. These campaigns/programs provide basic life and therapeutic skills, first aid training, medical check-ups, and hygiene information. Furthermore, these campaigns/programs arrange training sessions, workshops, and seminars where students are trained and taught about basic facts and new researches made in the medical field. Besides, knowledge about new emerging issues, problems, and solutions, it also provides awareness regarding diseases and preventions. It is a cross-sectional, quantitative research based on survey method. Data is collected from 60 respondents; 40 female students and 20 teachers, from 6 colleges of 2 towns of Karachi through Likert Scale, comprised of close-ended 43 structured items. The data is apprehended by taking SPSS Mean. It is a small effort
\end{abstract}


done to aid the conduction of medical awareness campaigns/programs as to aware students regarding health and medical information to the concern to meet challenges of the globalized world.

\section{KEYWORDS}

Medical Awareness Campaigns, Deliverance source, Therapeutic skills

\section{INTRODUCTION}

Education has the power to transform world entirely and evoke in a person the thrust of seeking knowledge. It aware students regarding many factorial aspects of life. Worldly, health is considered most significant in a person's life, concerning this students must get medical awareness in educational settings. Having good health state is principally needed, because one could only apprehend the surroundings and act accordingly when has better health condition. Even a single health issue is worrisome and hard to deal with, let alone having many issues simultaneously. Considering this, right guidance, proper knowledge and awareness is adequately required as it paves way for medical awareness campaigns/programs to be provided for students. Medical awareness campaigns deliver extensive information about health. Students these days are involved in many unhealthy habits and activities. So to educate them for health and hygiene, nutritionist points, health issues and problems, many bodily and hormonal changes, mental disturbances, oral health, viruses and vaccinations, injuries and infections, many precautionary measures and cures, general and specific diseases, significances of medical check-ups, first aid treatments and many other health related information; medical awareness campaigns are of highly importance. Medical awareness campaigns provide information about medical innovations made and all the new equipment made to ease lives of lay men, as; self-operating Blood Pressure machines, Blood Sugar checking machines, Digital Thermometers, and much more. Moreover, these campaigns help building ability to understand medical factors better. Aware students could also guide others later in their private and professional lives. But most importantly, these should be scheduled timely to consistently aware students to take better care.

Apart from simple influenza, cold, headaches, coughs, and other such issues, there are diseases which need prolong treatment or are lifelong - the chronic diseases. Medical campaigns guide about such diseases, dispel decades made myths relating a few of them, convey possible precautionary means, impart course based treatments and emphasis on their medicines' regularity. Chronic diseases are making many people suffer worldwide causing more than two thirds of the deaths (Raghupathi \& Raghupathi, 2018). These are long-lasting diseases for 3 months or even more. The 
$\overline{\text { U.S. National Center for Health Statistics describes; vaccinations or medications could }}$ normally not cure them, nor are they easily vanished. Most chronic diseases are caused by bad dietary routines, less physical activities, and tobacco usage. Chances of chronic diseases increase with the age. These are; Arthritis, Cardiovascular diseases; Heart attacks, and Strokes, Cancer; Breast cancer, Diabetes, Epilepsy and Seizures, Obesity, and Oral health problems (Shiel, 2018, "Medical Definition of Chronic disease", para 1 \& 2), Hypertension and Respiratory diseases are also included in chronic diseases. These diseases could cause hospitalizing, prolonged disability, deceased life quality, and even lead to death mostly (National Conference of State Legislatures, 2013).

Students timely face many phases, some of which they are conscious, but for some appropriate guidance is needed. Sometimes new diseases and viruses emerge and rapidly spread requiring immediate precautionary steps taken. This indicates conduction of awareness campaigns/programs from initial educational level, at least for college students mandatorily, because they are sufficiently intellectual at this age, precisely perceive society, could understand things better and are on the wits of delivering information to friends, cousins, relatives, and others. Adding up, they undergo many bodily and hormonal changes and experience many adolescence facts at this age, which could probably cause mental issues if are left undiscussed and unexplained, leading towards serious and erroneous steps. They become more social, observe and explore surroundings, thus having more chances of getting infected. Socialization familiarized them with different diseases and disorders. There is a chance of witnessing life-threatening conditions, and being aware they could save a life by providing first aid. It shows the necessity of medical awareness campaigns in colleges. Sometimes, excessive examinations' stress cause anxiety, depression, and other mental disorders, which is frightening for students' health, while giving them awareness as how to cope up in such conditions and to stay calm and relaxed; is the better way out for them. These programs guide students to adopt adequate lifestyle. Medical awareness campaigns build knowledge, skills, sense of self-care and sincerity towards their health and environment. Simultaneously, these days society is also contacted with lethal elements, concerning to make children knowledgeable about all the bad influential facts, to make them embrace positive habits and routines right from beginning which could be handled by making children aware of good and bad health routines and lifestyles (Amin \& Amini, 2009). Hygiene is such an act comprised with cleaning ambiances in contact to people by the people to sustain better health form. Maintaining good health state requires sincere efforts. All it takes to stay concerned for hygiene, is adopting a balanced diet having all portions in required amounts of carbohydrates, vitamins, minerals, fats, and proteins. Regularly getting engaged in sufficient exercises and physical activities, having plenty of water intake, proper sleep, 
healthy breakfasts, lunches, and dinners, keeping an eye on weight, try being more dependable on natural food materials and contacting with natural settings as having walks in fresh air or breathing fresh air, use boiled water, allowing direct sunlight to entre homes. Engaging in physical activity on daily basis supports many health conditions, decreases fatal diseases risks, and helps in slumber as well. Working out for 20 to 40 minutes every day or on the very least four to five days every week continuously, is averagely suggested (Hedge, 2003). Many studies are done showing benefits of physical involvement for better health. Daily physical activities reduce chances of cardio diseases, cancer and also helps reducing high blood pressure, diabetes, obesity, and bones and joints issues (Warburton, Nicol, \& Bredin, 2006). Personal hygiene includes better oral health as well. Oral health is taken as having better teeth, it is linked with general health and is necessary for better health condition. Having good oral health prevents all oral diseases and disorders. Having the check over oral conditions could diagnose deficiencies and diseases. Bad oral health puts its effects on life of a person, like, pain, eating issues, ruined or stained teeth, all these and other problems affect patients' routine life. Bad oral condition causes by extreme intake of alcohol, smoking or any other form of tobacco, and imbalanced diet (Petersen, 2003). A healthy student would never become the transmitting reason of infections and viruses because of stronger immune system by adopting health and hygiene rules. As also stated by Male, Brostoff, Roth, \& Roitt (2015, pp. 3, \& 289290) that infections from the strong immunity people do not transmit to other individuals. Moreover, some females at this age experience many menstrual problems and some might even be facing with PCOS, which is an alarming condition for young girls. This rapidly increasing issue is mainly the reason of hormonal changes which is being seen adversely these days in young girls. As explained by Naveed, Ghayas, \& Hameed (2015), any disturbance in normal hormonal activities results in menopause. The reason behind could be contraceptive medications and hormone replacement therapy (HRT), stress, imbalance diet, bad atmospheric contact, excessive intake of non-organic items, animal products having undue quantity of estrogen, and cosmetics. They could be cured by taking antibiotics, herbal and homeopathic medications, and proper diet. They show symptoms of irregular menstruation acne, oily skin, fever, fatigue, excessive hair growth, dizziness, anxiety, allergy, low sexual desire, weight gain, headaches, water retention, endometriosis, urinary tract infections (UTI's), and premenstrual syndrome (PMS). On the other hand, some girls also get married either in college or right after passing out from college, so giving awareness related to the gynecologic issues is all made easy through these organized campaigns, programs, and medical check-ups, where students could easily talk about their quarries and problems. Awareness programs could be conducted using many ways as the delivery sources to spread knowledge regarding first aid measures and to provide the chance of personally 
practicing how to provide first aids. Medical campaigns also facilitate the arrangements of medical check-ups timely as to know about students' health conditions. Developed countries of this era also emphasize on such campaigns and programs and make sure that the medical check-ups and awareness programs are being done in their educational institutes to educate students and to maintain the records as well. Thus, this enhances the essentiality of medical awareness campaigns and their conduction in colleges so students could be led on right paths and they could follow a good lifestyle, else they might chase after the wrong routines.

\section{LITERATURE REVIEW}

Awareness is the most delicate and emphasizing process through which an individual's mind could be filled with true and real information. It educates people about relevant information and makes people discriminate among good and bad habits, rituals, and eliminates misconceptions. Arp (2007) explains about awareness that, it is such of a conscious experience which requires interrelation of one's surrounding with its nervous system, so that one could completely understand about real facts and happenings. Awareness could be given about anything where a lack is noticed but importantly this process should be continuous and properly managed. Similarly, college students should be provided with medical awareness regarding various issues and aspects and they must be educated in this manner. Medical awareness is such of an awareness which engraves each and every part related to medical field which is provided to students to make them aware about some particular facts. Whether these are health related issues or information, new researches or the techniques introduced, whatever it might be, medical awareness events include them all. Such awareness is given by systematically organized campaigns and programs vastly.

Campaigns are well - organized and planned events for delivering facts to audience, they have educated, trained staff, including experts, specialists, and majors of their particular departments. They go by their certain goals and basic rules to achieve desired objectives, whereas programs are the series of systematically designed events which include different activities. Project Management Institute (as cited in Weaver, 2010, p. 2) states, programs are the interrelation of many projects or activities, which also convey results which are beneficial for some organization or anything the program is conducted for. Programs offer many such activities which provide their attendees to participate in them and gain experiences. Most of the programs give commemorative certificates to audiences as well, which bears the importance and is a proof of individual's engagement in that particular program. Implementing both these methods in colleges would yield beneficial outcomes in terms to aware and educate college students. Students these days are tend to adopt bad habits and acquire inaccurate life 
style which in the end effects not just students' life but also people around them. So, it is necessarily important that students are provided with medical awareness campaigns/programs, as these are the instructive schemes planned for raising health related information. Looking back in time, these awareness raising events have a very long history and are being done since ages. The very first awareness raising campaigns, with the collaboration of public advertising groups were related to family planning. From the late 1960s these are being used in different public health areas, through which facts are delivered which emphasize on information, social customs, awareness, and are useful in convincing to adopt healthy attitudes (Robinson et al, 2014). Giving medical awareness to college students has many significant factors, and regarding the essentiality of this, such facilities of giving awareness are provided in many educational institutes around the world. School health care started in late $18^{\text {th }}$ and early $19^{\text {th }}$ centuries in Europe. England and United States started off with food services in schools then included medical facilities and physical educations as well. In 1890s United States provided Doctors within the schools, who had to protect students from infectious diseases, but it expanded to embrace medical check-ups, health education, and providing healthy environment within the premises of school, and that is how school health care advanced to offer education to local communities from simply being a school health care management services (Shin, 2013).

Literally, providence of medical information to students especially college students has become a very significant aspect, as students could be trained and enlightened through these events about the unknown phenomena and basic information. Students in their growing ages, mostly in their adolescent's period do not much care about health and hygiene rules, which makes them exposed to various diseases, in fact they are attracted to all the unhealthy snacks and junk foods, instead of nutritionist foods, which lead to obesity issues. They also do not care about proper balanced and nutritious diet. While actually having a full nutrients food is very important in growing age children because specific missing nutrients cause specific deficiency and to overcome the deficiency it is needed to take that particular missed nutrient back in diet, because imbalanced diet and inactivity causes many diseases (Schiff, 2011, pp. 5-6, \& 65). However, this condition could be controlled by enabling children distinguish between good and bad health routines and lifestyles through Health Awareness programs and campaigns (Amin \& Amini, 2009). WHO (World Health Organization) proposed in September 2013 a program of nutrition friendly schools in 17 countries from Europe, it covers all levels of schools; preschools to high schools, and turkey is among those countries who have joined hands in this program. They are focused in providing nutrition educations, physical training lessons to students (Uğur Baysal \& İnce, 2018). Academic stress and anxiety, and the anxiety caused by hormonal and bodily changes 
is common in children at this age, and becomes yet another reason of either mental disorders or mental disturbances. These hormonal changes could either be normal ones as per the requirement of age or there could be imbalanced hormonal changes, but whichever it is, if students are unaware of these facts it could also turn into a traumatic situation for students. Especially female students are more prone to such disturbances and fluctuations of hormones. Hormonal activities are a lot significant in a woman's body. Any changing or imbalance effects on the woman's mood, sexual desire, ovulation and fertility (Naveed, Ghayas, \& Hameed, 2015). Hence, being unaware directly effects on the psyche of students. Moreover, many students secretly suffer from mental health disorders or even are depressed, and negligence of people around them never let those students speak up and they are left being in such state which sometimes becomes the reason of bold steps as taking their own lives. Spreading awareness as how to keep a good health, and to restrict from attitudes which affect mental health is highly important cause that is the only way to save not just the mental health but also the lives of many. Salerno (2016), mentions that $46.3 \%$ adolescents suffer from mental disorders. Further stating, the study mentions that mostly occurrence of mental illness arises before children hit the age of 20, and it takes them to suicidal attempts which makes it the third dominating reason of deaths in children aging from 10 to 19 , and an end could be put on this only by educating adolescents to treat their worst mental health scenarios. As stated by Jack-ide (2016), one out of every five children is noted with suffering in some sort of mental or emotional disorders, so literary events must be organized for adolescents to make them aware of mental health conditions and make them opt for positive behaviors instead of drifting towards negative behaviors, as such attitudes could become rigid and are seen in their adulthood as well.

Another key feature of these medical awareness campaigns and programs is the providence of information about first aid measures. Students are offered with handson practices for treating injured while the paramedics or doctors are not around, extensively including, these events also arrange timely check-ups for students. According to CDC (2017), taking complete medical examinations enhances chances of having better life state, in addition, these campaigns and programs facilitate students with medical check-ups timely and keep a systematic record of every student within the college premises. A research done by Shin (2013), mentions that in Korea school health care programs focus on health care services, health education and counseling, and local social health services. This program shares a system of health examination; "The Student Health Examination (SHE)." It aims in setting tactics for protecting, training, and early diagnosis of diseases, providing health consultation, remedies, and caring early-diagnosed disorders' students, the third aim is to make strategies for the 
advancement and development of student health care programs in the light of results from SHE, and maintain basic health indicators.

Given all that, worldwide mostly countries make these facilities available in educational institutions for their students, they adequately guide, council, and educate students to make them lead a better life ahead. Having some search done shows how different countries are working in the manner of educating students and in providing health education, awareness, and involving them in healthy activities. Developed countries around the world maintain conduction of medical awareness campaigns and programs in their educational institutions timely. They have properly built infirmaries in their educational institutions, where they have the records of every student's health background as well. These countries also organize medical check-ups, where the height, weight, mental conditions, oral health, physical health, and diets are checked by their specialists, and all these are noted carefully and are followed up. Health tips are taught to students, and they are motivated to participate in healthy activities which help to maintain their health. This sense is developed only because medical awareness programs are being conducted in educational institutions since forever. Mentioning a study conducted in India related to health awareness and behavior of high school students of Maharashtra's schools, where most of the students were aware of health conditions (Mehta \& Bhat, 2015). Similarly, Turkish schools are nowhere to be left behind in this thoughtful act of educating students, a research done in Turkey shows the measures taken for health in schools. The special program named "Child Health Program" has been conducting for children-related many issues and it has made successful results as well. Since 1982, by the Turkish Ministry of Education Department of Health with collaboration of institutions, 1.5 million primary students were checked yearly. Moreover, many projects are designed for Turkey's school health (Uğur Baysal \& İnce, 2018). A non-profit organization (NPO), 'TELL' works for International Japanese Community in providing support and counseling services as well as mental health care needs ever since 1973. This organization works to educate teenagers by sending trained volunteers in international schools and in schools with higher ratio of returnee Japanese students. This organization runs the Lifeline School Awareness Program (Tell, n.d.). Korea began health care program in its schools in late $19^{\text {th }}$ century with its new educational system. Under the Number 1 Law of School, at Hansung Teacher Training School it was made mandatory for students to take part in physical activities and follow self-hygiene rules, and Hygiene and Physical education were introduced. With the Education commandment 89, all schools were to schedule students' physical check-ups and provide care giving equipment to advance health facilities of schools. The School Health Act (Article 7396) was reviewed in 2007 and oral examination for elementary students, mental health, and health-related educational 
programs for students were also added up in the responsibilities of schools, in this manner school health care program kept progressing constantly (Shin, 2013). All these reviewed literatures from different regions of world openly show that health is considered an important part of human life, and health care measures and educations are provided in schools considering its importance, as to bring up children in the healthy manner with healthy attitudes.

But, unfortunately, looking in the educational system of Pakistan does not show such tremendous efforts and steps in educating and in the awareness of students. Even if some work is being done in this regard, that is only up to very limited area and still college level is not so far touched by those works. College level is the mostly neglected area in this accord. Gulzar (2008), a member of nursing department in a private university of Karachi, says, no effort is being put in promotion and education of health in Pakistan's education institutions. She further emphasizes on the effectiveness of conducting awareness programs in schools that it helps building supportive behavior for health conditions among teachers and students, which includes physical education, counseling, training, and vigorous behavior in schools. Recommended as she said, having a trained and capable nurse within school premises helps enhancing healthy environment. Having follow up of food provided in schools' cafeterias and vendors outside by the school authorities. As schools make child into a man it would be very important to provide a healthy living style for children and educate them from beginning so that all this could be transmitted to others later in time when the child grows up having good healthy habits, and could make a reliable nation. A research done by four researchers of Ziauddin Medical University, Karachi and of Karachi University; from the departments of Community Health Sciences and Family Medicine collaboratively, aimed to find whether female students of Karachi's colleges know about some common diseases. The research showed an adequate number of students knowing about the HIV/AIDS, but an insufficient level of students knowing about the transmission of Typhoid and Hepatitis B and C. Concluding, it says that research done in this respect arises the need and essentiality of health education campaigns for infectious diseases among young female students (Khan, Anjum, Khan, \& Nabi, 2005). Health education, medical check-ups, or any kind of medical awareness campaigns or/ and programs are not being conducted in educational institutes of Pakistan in large scale. It is not that there are no programs entirely conducted in schools or in any other educational institutions, but they are so little in number that it is not making vast difference in students' health. In fact, if any campaign or/and programs are being arranged, they mostly are not by governmental officials, but by some NGOs or NPOs, and are not conducted at college levels either, especially public colleges. It thrusts up the need of scheduling such efforts in Pakistan's education institutions. Bashah 
mentioned (as cited in Saleem, 2017), that awareness campaigns help convincing public to bring about the change in their lives, like in their eating and exercising behaviors. Awareness campaigns in different regions aware their public about many aspects as healthy eating, physical activities, obesity, precautions for diseases, and everyday life's illnesses. These campaigns inspire people switch to healthy lifestyles. This act of raising awareness has also been adopted by some of the schools which indeed is a good step.

\section{RESEARCH OBJECTIVES}

1. To identify the extent to which the medical awareness campaigns are essential to students for having practical approach regarding diseases.

2. To find as to what extent the college administration is supporting for medical awareness campaigns and programs.

3. To investigate students' perception and interest regarding medical awareness campaigns/programs.

4. To emphasize that the lack of medical awareness programs affect students' health, individually as well as results lack of progression within society.

5. To identify if the medical check-ups are scheduling in colleges accordingly / regularly.

6. To promote the conduction of medical check-ups and awareness sessions in colleges. 7. To publicize the necessity of medical awareness campaigns and programs at every level, especially; the college level, both on public and private sectors.

\section{RESEARCH HYPOTHESES}

1. Medical awareness campaigns and programs will be essential because they are the main deliverance source for the perception of collective medical facts as well as for a quality life.

2. College students will be needed to attend the medical awareness campaigns and programs.

3. College students will perceive they should get examined through medical check-ups timely arranged by college administration.

4. Lack of medical awareness will affect students' health and wellbeing of society.

5. Conducting awareness campaigns and programs will enhance health perception and life skills for better living among students.

6. Medical awareness campaigns and programs will aid in polishing basic therapeutic skills and will provide needful information.

7. Appropriate standards should be followed for health facilitations by colleges.

8. Colleges' administration would take initiative in the conduction of medical awareness campaigns and programs. 


\section{RESEARCH METHODOLOGY}

It is a cross-sectional, quantitative research based on survey method. For sample selection simple random sampling is used, whereas population is public colleges of Karachi, target population is two towns of Karachi, and sample is drawn from six colleges, which is $50 \%$ of the targeted population, which are 60 in total, aged from 15 to 53, out of which 40 are female student participants and 20 are teacher participants.

For the data collection Likert scale is used comprised of forty three close-ended, structured questions, having five point degree of freedom. The pre-testing of questionnaire has been done on 10 different participants. Analysis of data has been done by using Percentage. The data is also apprehended by taking the SPSS mean.

\section{RESEARCH FINDINGS}

Table 1: $\quad$ Frequency Table for the sample specifications

\begin{tabular}{llccc}
\hline Respondents & Gender & Age & Frequency & Percentage \\
\hline Teachers & Female & $35-53$ & 20 & $33.33 \%$ \\
Students & Female & $15-20$ & 40 & $66.66 \%$ \\
\hline
\end{tabular}

Above table shows frequencies of samples of research, which is, out of 60 sample size, 20 respondents are teachers which makes $33.33 \%$ of the sample size, aging from 35 to 53 , and 20 respondents are students which makes them $66.66 \%$ of the overall sample size, aging from 15 to 20 . Other than that, both the samples are females.

\section{Proportion of Teachers and Students in Sample}

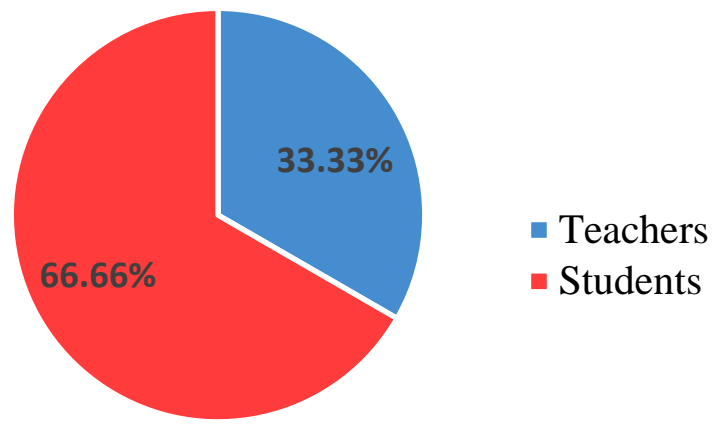

Figure: Proportion of Teachers and Students in Sample 


\begin{tabular}{|c|c|c|c|c|c|c|}
\hline \multirow{3}{*}{$\begin{array}{l}\text { Table 2: } \\
\text { Hypotheses } \\
\end{array}$} & \multicolumn{6}{|c|}{ Statistical Description of the Teachers' Data } \\
\hline & \multicolumn{6}{|c|}{ Teachers $(\mathrm{N}=20)$} \\
\hline & SA & $\mathbf{A}$ & $\mathbf{N}$ & D & SD & Mean \\
\hline $\mathrm{H}=1$ & $40 \%$ & $60 \%$ & $0 \%$ & $0 \%$ & $0 \%$ & 4.4 \\
\hline $\mathrm{H}=2$ & $30 \%$ & $60 \%$ & $10 \%$ & $0 \%$ & $0 \%$ & 4.2 \\
\hline $\mathrm{H}=3$ & $60 \%$ & $40 \%$ & $0 \%$ & $0 \%$ & $0 \%$ & 4.6 \\
\hline $\mathrm{H}=4$ & $60 \%$ & $35 \%$ & $5 \%$ & $0 \%$ & $0 \%$ & 4.55 \\
\hline $\mathrm{H}=5$ & $60 \%$ & $30 \%$ & $0 \%$ & $0 \%$ & $0 \%$ & 4.4 \\
\hline $\mathrm{H}=6$ & $70 \%$ & $30 \%$ & $0 \%$ & $0 \%$ & $0 \%$ & 4.7 \\
\hline $\mathrm{H}=7$ & $60 \%$ & $25 \%$ & $15 \%$ & $0 \%$ & $0 \%$ & 4.45 \\
\hline $\mathrm{H}=8$ & $60 \%$ & $30 \%$ & $10 \%$ & $0 \%$ & $0 \%$ & 4.5 \\
\hline $\mathrm{H}=9$ & $65 \%$ & $35 \%$ & $0 \%$ & $0 \%$ & $0 \%$ & 4.65 \\
\hline $\mathrm{H}=10$ & $55 \%$ & $35 \%$ & $10 \%$ & $0 \%$ & $0 \%$ & 4.45 \\
\hline $\mathrm{H}=11$ & $70 \%$ & $25 \%$ & $5 \%$ & $0 \%$ & $0 \%$ & 4.65 \\
\hline $\mathrm{H}=12$ & $65 \%$ & $20 \%$ & $10 \%$ & $0 \%$ & $0 \%$ & 4.45 \\
\hline
\end{tabular}

The given table showing statistics of teachers' sample, done by percentage and taking statistical mean. Mostly respondents' answers lay on strongly agreed and agreed. Percentages of each hypothesis are on the strongly agreed and agreed with highest figures as compared to the neutral, disagreed and strongly disagreed. The Likert scale is 5 point scale, with strongly agree as being 5 to strongly disagree as being 1 , and mean of each hypothesis is shown between strongly agreed and agreed with the least figure 4.2 to the highest 4.7 . They all shown to lean towards strongly agreed and agreed, hence, proving hypotheses correct.

Table 3: $\quad$ Statistical Description of the Students' Data

\begin{tabular}{lcccccc}
\hline Hypotheses & \multicolumn{2}{c}{ Students } & (N = 40) & & & \\
\hline & SA & A & N & D & SD & Mean \\
\hline $\mathrm{H}=1$ & $47.5 \%$ & $52.5 \%$ & $0 \%$ & $0 \%$ & $0 \%$ & 4.47 \\
$\mathrm{H}=2$ & $50 \%$ & $40 \%$ & $10 \%$ & $0 \%$ & $0 \%$ & 4.4 \\
$\mathrm{H}=3$ & $60 \%$ & $37.5 \%$ & $2.5 \%$ & $0 \%$ & $0 \%$ & 4.57 \\
$\mathrm{H}=4$ & $55 \%$ & $37.5 \%$ & $7.5 \%$ & $0 \%$ & $0 \%$ & 4.47 \\
$\mathrm{H}=5$ & $55 \%$ & $37.5 \%$ & $5 \%$ & $2.5 \%$ & $0 \%$ & 4.45 \\
$\mathrm{H}=6$ & $47.5 \%$ & $50 \%$ & $2.5 \%$ & $0 \%$ & $0 \%$ & 4.45 \\
$\mathrm{H}=7$ & $52.5 \%$ & $37.5 \%$ & $7.5 \%$ & $2.5 \%$ & $0 \%$ & 4.4 \\
$\mathrm{H}=8$ & $65 \%$ & $25 \%$ & $10 \%$ & $0 \%$ & $0 \%$ & 4.55 \\
$\mathrm{H}=9$ & $42.5 \%$ & $52.5 \%$ & $5 \%$ & $0 \%$ & $0 \%$ & 4.37 \\
$\mathrm{H}=10$ & $50 \%$ & $45 \%$ & $5 \%$ & $0 \%$ & $0 \%$ & 4.45 \\
$\mathrm{H}=11$ & $47.5 \%$ & $50 \%$ & $2.5 \%$ & $0 \%$ & $0 \%$ & 4.45 \\
\hline
\end{tabular}




\begin{tabular}{lllllll}
\hline $\mathrm{H}=12$ & $50 \%$ & $42.5 \%$ & $5 \%$ & $2.5 \%$ & $0 \%$ & 4.4 \\
\hline
\end{tabular}

The given table showing statistics of students' sample, done by percentage and taking statistical mean. Mostly respondents' answers lay on strongly agreed and agreed. Percentages of each hypothesis are on the strongly agreed and agreed with highest figures as compared to the neutral, disagreed and strongly disagreed. The Likert scale is 5 point scale, with strongly agree as being 5 to strongly disagree as being 1 , and mean of each hypothesis is shown between strongly agreed and agreed with the least figure 4.37 to the highest 4.57 . They all shown to lean towards strongly agreed and agreed, hence, proving hypotheses correct.

Table 4: $\quad$ Statistical Description of the Teachers' and Students' Data

\begin{tabular}{lcccccc} 
Hypotheses & \multicolumn{2}{l}{ Teachers $(\mathbf{N}=\mathbf{2 0})$} & \multicolumn{2}{l}{ Students $(\mathbf{N}=\mathbf{4 0})$} \\
\hline & SA & A & N & D & SD & Mean \\
\hline $\mathrm{H}=1$ & $45 \%$ & $55 \%$ & $0 \%$ & $0 \%$ & $0 \%$ & 4.45 \\
$\mathrm{H}=2$ & $43.3 \%$ & $46.6 \%$ & $10 \%$ & $0 \%$ & $0 \%$ & 4.33 \\
$\mathrm{H}=3$ & $60 \%$ & $38.3 \%$ & $1.6 \%$ & $0 \%$ & $0 \%$ & 4.58 \\
$\mathrm{H}=4$ & $56.6 \%$ & $36.6 \%$ & $6.6 \%$ & $0 \%$ & $0 \%$ & 4.5 \\
$\mathrm{H}=5$ & $56.6 \%$ & $35 \%$ & $3.3 \%$ & $5 \%$ & $0 \%$ & 4.43 \\
$\mathrm{H}=6$ & $55 \%$ & $43.3 \%$ & $1.6 \%$ & $0 \%$ & $0 \%$ & 4.53 \\
$\mathrm{H}=7$ & $55 \%$ & $33.3 \%$ & $10 \%$ & $1.6 \%$ & $0 \%$ & 4.41 \\
$\mathrm{H}=8$ & $63.3 \%$ & $26.3 \%$ & $10 \%$ & $0 \%$ & $0 \%$ & 4.53 \\
$\mathrm{H}=9$ & $50 \%$ & $46.6 \%$ & $3.3 \%$ & $0 \%$ & $0 \%$ & 4.46 \\
$\mathrm{H}=10$ & $51.6 \%$ & $41.6 \%$ & $6.6 \%$ & $0 \%$ & $0 \%$ & 4.45 \\
$\mathrm{H}=11$ & $55 \%$ & $41.6 \%$ & $3.3 \%$ & $0 \%$ & $0 \%$ & 4.51 \\
$\mathrm{H}=12$ & $55 \%$ & $35 \%$ & $6.6 \%$ & $3.3 \%$ & $0 \%$ & 4.41 \\
\hline
\end{tabular}

The given table showing collective statistics of teachers' and students' samples, done by percentage and taking statistical mean. Mostly respondents' answers lay on strongly agreed and agreed. Percentages of each hypothesis are on the strongly agreed and agreed with highest figures as compared to the neutral, disagreed and strongly disagreed. The Likert scale is 5 point scale, with strongly agree as being 5 to strongly disagree as being 1, and mean of each hypothesis is shown between strongly agreed and agreed with the least figure 4.33 to the highest 4.58 . They all shown to lean towards strongly agreed and agreed, hence, proving hypotheses correct.

\section{DISCUSSION}


The conducted study conceded results that both samples are in favor of conducting medical awareness campaigns/programs in colleges because they provide students effective information. Results practically show that samples secured their responses in favor that a lack could be seen in the medical information of students. Both the students and teachers feel a need of such events to be conducted and timely arranged in colleges for students' and society's well-being. Looking at collectively analyzed results, every hypothesis shows a great percent of strongly agreed and agreed and all the mean are leaning towards strongly agreed as well. Results showed 55\% of the samples are agreed that colleges are failed to provide these informatively events for their students, while it being the main deliverance source according to $46.6 \%$ of the samples. Medical check-ups are also found essentially needed and required by $60 \%$ of the samples and they are in favor of them being arranged timely in colleges as these check-ups are obligatory in an educational institution because as Virgini, Meindl - Fridez, Battegay, \& Zimmerli (2015) also said in their research; check-ups include methods which target individuals' complete health examining as per the age and gender. Further, periodic check-ups aim in taking case-history to record individuals' critical conditions, like blood pressure, and to know about their family history.

Results also show that $56.5 \%$ of the samples are strongly agreed on the statement that these awareness raising events help enhancing health perceptions and providing life skills among students, while 55\% are showing agreement in the therapeutic skills and information being provided by such events. As also stated in the work of Masiuliene, Looney, Aertgeerts, \& de Greef (n.d.) that, organizing an influenced and useful awareness raising campaign is very important in convincing audience to change their behaviors. By the results, $50 \%$ of the samples are strongly agreed that conducting medical awareness campaigns and providing hands-on practices regarding first aids develops in students the ability to handle injuries, deal with personal issues and problems, while $51.6 \%$ are convinced with the good impacts of these events and are agreed that these programs motivate students towards self-searching of information regarding health hygiene and different medical aspects. Results are openly showing an acceptance and requirement of these campaigns/programs to be mandatorily arranged for college students and as a responsibility of college administration to put some light over this neglected area as 55\% of the samples are strongly agreed on this notation. Moreover, $55 \%$ of the samples are also strongly agreed on the note that health facilities, health examinations, and such information providence events must follow internationally passed standards of the school health and hygiene.

A highly important aspect of human health is Mental Health. As said by Srivastava, Chatterjee, \& Bhat (2016) being unaware becomes the reason of negligence of mental 
health, for it to be taken good care of, mental awareness are ways to build awareness, this role could also be played by communities in low-income countries, and they have shown good results as well. In the way, such campaigns/programs also aware about mental disorders and disturbances, their symptoms, cures and cautions to students. Indicating about the effectiveness of students' knowledge regarding medical information, Goel \& Singh (2007) say that, accurately enlighten students as how to handle the injuries and illnesses is very efficient, as it not only benefits their own heath conditions but such educated and informed students are also helpful for society and advantageous in critical situations while paramedics are unapproachable.

All these efforts should be monitored properly and most importantly, these campaigns and programs must be repeated timely throughout the year. There are many ways used to deliver information as educational institutions are adopting AV-Aids for the quality education. In the same manner, they could be adopted to provide medical awareness to students. These could also be conducted using other sources, as mass media, social media, public relations, demonstrations, tours, and leaflets. They could be spread by conducting workshops for college students, arranging seminars, making awareness raising groups or pages on socializing websites, introducing health education as a subject, where specialized teachers would educate students regarding medical information, scheduling psychiatrists' or psychologists' sessions in every two weeks, or once in a month, where these professionals would teach students related to many factorial aspects, and by conducting special hands-on-experiencing programs students would practically perform first aid treatments as well.

\section{RECOMMENDATIONS}

1. In the light of all the research work, possible measures should be taken regarding health facilitations and medical awareness campaigns/programs and check-ups should be organized with the specialist/experts from concerned fields. Keeping in mind that all these efforts would only give out best results when are arranged timely and constantly around the year to provide better understanding regarding important issues, problems, and medical facts, because this develops interest and motivation in students to be the part of them.

2. It is necessary for governmental officials to step in and take serious actions to conduct medical awareness campaigns/programs, and for this government should allocate an appropriate amount of funds for due purpose.

3. In addition, the staff participating and organizing members of medical awareness campaigns/programs should also be given incentives from concerned authorities or government.

4. Training sessions and workshops should be planned in colleges related to various 
life skills to train students for basic skills and strategies in emergency situations. Students must be taken to places where lifesaving trainings are conducted for their participation through hands-on practices for related situations.

5. The quality infrastructure of colleges also needs some attention. The infirmaries in most of the colleges are either missing or need some serious fixations. The facilities and ambiance there are near to nothing. All this should be provided based on internationally followed standards passed by ISO to cater the required needs and quality of health facilities. More importantly, regular monitoring and supervision must be done by concerned authorities or government as to provide better facilitations and working environment.

6. Parents should be given opportunity to involve in such campaigns/programs and should be aware of their children's health conditions, for two purposes; firstly to let the parents know about their children's condition and secondly to collect and record the data regarding students' health background habits.

7. Timely health check-ups must be arranged and students' complete health records should be maintained. Besides, these records must be accessible to concerned students, their parents, and their teachers.

8. Yet another big step could be taken for students, is to establish guidance and counseling units. These units should be built in colleges where students could discuss their problems/issues regarding their health with consultants.

\section{REFERENCES}

Amin, D., \& Amini, M. (2009). Health Awareness [PDF File]. Retrieved from https://www.uio.no/studier/emner/matnat/ifi/nedlagteemner/INF4260/h09/student\%2 0projects/health-awareness/Health\%20Awareness-midterm-report.pdf

Arp, R. (2007). Consciousness and Awareness: Switched - On Rheostats: A

Response to de Quincey [PDF File]. Journal of Consciousness Studies, 14(3), 101

-103 . Retrieved from

https://www.google.com/url?sa=t\&source=web\&rct=i\&url=https://pdfs.semanticsch olar,org/8f26/3beba343da98ca469c2b400378d04fb4debd.pdf\&ved=2ahUKEwjXoOj wn57nAhWQy4UKHV90AXgQFjALegQIARAB\&usg=AOvVaw3WEXZOfPIFoTVEcAeSY0g

CDC (2017). Regular Check-ups are Important: Why are Check-ups Important? Retrieved March 13, 2020, from https://www.cdc.gov/family/checkup/index.htm

Goel, S., \& Singh, A. (2007). Health Awareness of High School Students. Indian Journal of Community Medicine, 32(3), 192 - 194. Retrieved from Health awareness of high school students Goel S, Singh A - Indian J Community Med (ijcm.org.in)

Gulzar, S. (2008). Promoting School Health in Pakistan. Retrieved March 26, 2020, from https://www.interface.edu.pk/students/June-08/School-health-promotion.asp 
Hegde, B. M. (2003). Health Benefits of Exercise [PDF File]. Japi, 51, 297 - 298. Retrieved from https://pdfs.semanticscholar.org/b379/6ab34f3dbf3f80968db384e9247f6a373626.pdf

Jack- ide, I O. (2016). Secondary School Students Awareness and Attitudes towards Mental Health Disorders in Bayelsa State, Nigeria. Annals of Behavioral Science. Retrieved from https://behaviouralscience.imedpub.com/secondary-school-students-awarenessandattitudes-towards-mental-health-disorders-inbayelsa-state-nigeria.php?aid=11189

Khan, S. J., Anjum, Q., Khan, N. U., \& Nabi, F. G. (2005). Awareness about Common Diseases in Selected Female College Students of Karachi. Journal of Pakistan Medical Association 55(5). Retrieved from https://jpma.org.pk/

Male, D., Brostoff, J., Roth, D. B., \& Roitt, I. M. (2018). Immunology: Introduction to the Immune system, \& Vaccination $\left(8^{\text {th }}\right.$ ed.). : Elsevier Saunders.

Masiulienè, L., Looney, J., Aertgeerts, H., \& de Greef, M. (n.d.). The Key Features of Successful Awareness Campaigns [PDF File]. Retrieved from http://www.elinet.eu/fileadmin/ELINET/Redaktion/user_upload/The key_features_o f_successful_awareness_raising campaigns 10-15_LM_ELINET.pdf

Mehta, V. Bhat, A. (2015). Health Awareness and Behavior among Adolescent Students in Rural School: A Cross Sectional Observation Study. International Journal of Research in Medical Sciences, 3(12). DOI: http://dx.doi.org/10.18203/2320$\underline{\text { 6012.ijrms20151231 }}$

National Conference of State Legislatures. (2013). Chronic Disease Prevention and Management [PDF File]. Retrieved from https://www.ncsl.org/documents/health/chronicdtk13.pdf

Naveed, S., Ghayas, S., \& Hameed, A. (2015). Hormonal Imbalance and Its Causes in Young Females [PDF File]. Journal of Innovations in Pharmaceuticals and Biological Sciences, 2(1), 12 - 16. Retrieved from http://www.jipbs.com/VolumeArticles/FullTextPDF/38_JIPBSV2I103.pdf

Petersen, E. P. (2003). The World Health Report 2003: Continuous Improvement of Oral Health in the 21st Century - The Approach of the WHO Global Oral Health Programme [PDF File]. Retrieved from https://www.who.int/oral_health/media/en/orh_report03_en.pdf

Raghupathi, W., \& Raghupathi, V. (2018). An Empirical Study of Chronic Diseases in the United States: A Visual Analytics Approach to Public Health. International Journal of Environmental Research and Public Health 15(3), 431. DOI: 10.3390/ijerph15030431

Robinson, M. N., Tansil, K. A., Elder, R. W., Soler, R. E., Labre, M. P., Mercer, S. L. The Community Preventive Services Task Force. (2014). Mass Media Health Communication Campaigns Combined with Health-Related Product Distribution: A Community Guide Systematic Review [PDF File]. American Journal of Preventive Medicine 47(3), 360 - 371. Retrieved from https://www.thecommunityguide.org/sites/default/files/publications/healthcommAJPM-evrev-campaigns.pdf

Saleem, F. (2017). Health awareness Campaigns Have Positive Impact: Expert. The 
Peninsula. Retrieved from

https://www.thepeninsulaqatar.com/article/14/02/2017/Health-awarenesscampaigns-have-positive-impact-Expert

Salerno, J. P. (2016). Effectiveness of Universal School-Based Mental Health Awareness Programs among Youth in the United States: A Systematic Review. The Journal of School Health, 86(12), 922 - 931. DOI: 10.1111/josh.12461

Schiff, W. J. (2011). Nutrition for Healthy Living: Nutrition: The Basics, What Is an Essential Nutrient?, \& Dietary Guidelines ( $2^{\text {nd }}$ ed.). USA, New York: McGraw-Hill.

Shiel, W. C. Jr. (2018). Medical Definition of Chronic disease. Retrieved February 09, 2020, from https://www.medicinenet.com/script/main/art.asp?articlekey=33490

Shin, H. (2013). The Current Status of Korean Student Health Examination. Korean Journal of Pediatrics, 56(8), 313 - 322. DOI: 10.3345/kjp.2013.56.8.313

Srivastava, K., Chatterjee, K., Bhat, P. S. (2016). Mental Health Awareness: The Indian Scenario. Industrial Psychiatry Journal 25(2), 131 - 134. DOI: 10.4103/ipj.ipj_45_17

Tell. (n.d.). Lifeline School Awareness Program. Retrieved March 24, 2020, from https://telljp.com/outreach/schoolawareness/

Uğur Baysal, S., \&İnce, T. (2018). Recent Developments in School-Based Health Services in Turkey. The Journal of Pediatric Research, 5(2), 60 - 64. Retrieved from http://jpedres.org/

Virgini, V., Meindl - Fridez, C., Battegay, E., \& Zimmerli, L. (2015). Check-up Examination: Recommendations in Adults [PDF File]. Swiss Medical Weekly, $1-11$. Retrieved from https://pdfs.semanticscholar.org/452d/890362d263b1e00b998188a5be9c71dd0215. pdf

Warburton, D. E. R., Nicol, C. W., \& Bredin, S. S. D. (2006). Health Benefits of Physical Activity: The Evidence. CMAJ 14(6), 801 - 809. DOI: 10.1503/cmaj.051351

Weaver, P. (2010). Understanding Programs and Projects Oh, There's a Difference! [PDF File]. Retrieved from https://www.mosaicprojects.com.au/PDF_Papers/P078_Programs_Projects_Full_Pa per.pdf 